\title{
Toward a proximal cognitive model of co-morbidity: Predicting individual differences in reading, writing and maths
}

\author{
P. Zoccolotti ${ }^{1,2,3}$ \\ ${ }^{1}$ Sapienza University of Rome, \\ 5 Aldo Moro Sqr., Rome 00185, Italy \\ ${ }^{2}$ Neuropsychology Unit, IRCCS Santa Lucia Foundation, \\ 306-354 Ardeatina Str., 00179 Rome, Italy \\ 3ISTC Institute for Cognitive Sciences and Technologies, \\ 44 S. Martino della Battaglia Str., 00185 Rome, Italy
}

\section{Zoccolotti Pierluigi}

e-mail: pierluigi.zoccolotti@uniroma1.it

Scopus AuthorID: 57207797178

ORCID: 0000-0002-6351-2455

(C) The Author (2019).

Published by Herzen State

Pedagogical University of Russia.

\section{Author:}

Abstract. We examined reading, writing, and mathematical skills in an unselected group of 129 Italian children attending fifth grade by testing various cognitive predictors for each behaviour. Models based on specific predictors explained more variance than control models based on "general" cognitive predictors. Cross-analyses indicated that predictors of reading accounted for performance in calculation much better than did general cognitive predictors, maths tests well predicted reading and so on. To interpret these results, we separately considered factors in terms of competence, performance and acquisition (automatization); this approach seems suitable to account for co-morbidity. Reading, writing and calculation skills depend on the development of discrete and different abstract competences (accounting for partial dissociations among learning disorders). By contrast, overlap among behaviours (co-morbidity) is accounted by defective acquisition in automatized responses to individual "instances"; this latter skill is item specific but domain general. Finally, performance factors may contribute to co-morbidity among learning behaviours.

Keywords: co-morbidity, reading, writing, maths, learning disabilities. 


\title{
К проксимальной когнитивной модели сопутствующих нарушений: прогнозирование индивидуальных различий в чтении, письме и математике
}

\author{
П. Дзокколотти ${ }^{1,2,3}$ \\ 1 Римский университет Ла Сапиенца, \\ 00185, Италия, Рим, пл. Альдо Моро, 5 \\ 2Научно-исследовательский институт госпитализации и здравоохранения, Фонд Санта Лючия, \\ 00179, Италия, Рим, ул. Ардеатина, 306-354 \\ 3Институт когнитивных наук и технологий при Национальном научно-исследовательском совете, \\ 00185, Италия, Рим, ул. Сан Мартино делла Батталья, 44
}

\section{Сведения об авторе:}

Дзокколотти Пьерлуиджи

e-mail: pierluigi.zoccolotti@uniroma1.it Scopus AuthorID: 57207797178

ORCID: 0000-0002-6351-2455

(C) Автор (2019).

Опубликовано Российским

государственным педагогическим

университетом им. А. И. Герцена.

Аннотация. Мы исследовали чтение, письмо и математические навыки в группе из 129 итальянских детей, посещающих пятый класс, путем тестирования различных когнитивных предикторов для каждого вида активности. Модели, основанные на конкретных предикторах, объясняют большую дисперсию, чем контрольные модели, основанные на "общих" когнитивных предикторах. Перекрестный анализ показал, что предикторы чтения учитывали производительность в вычислениях намного лучше, чем общие когнитивные предикторы, математические тесты хорошо предсказывали чтение и так далее. Чтобы интерпретировать эти результаты, мы отдельно рассмотрели факторы с точки зрения компетентности, производительности и приобретения (автоматизации). Этот подход кажется подходящим для учета сопутствующих нарушений. Навыки чтения, письма и счета зависят от развития отдельных, различающихся для каждого вида учебной активности компетенций (с учетом некоторых различий для разных видов нарушений обучения). В отличие от этого, совмещение нарушений (сопутствующие нарушения) объясняются нарушением автоматизированных ответов на отдельные “случаи”; этот последний навык является специфическим для предмета, но общим для области. Наконец, сопутствующим нарушениям обучения могут способствовать факторы производительности.

Ключевые слова: сопутствующие нарушения, чтение, письмо, математика, нарушения обучения. 
Introduction

Difficulties in learning to read, write or doing maths tasks are referred to as "specific" disturbances since they occur in the absence of deficits in general cognitive skills (intelligence) and neurological disorders, and in spite of regular attendance to school activities. Research on the cognitive antecedents of specific learning disabilities has been quite large; however, it has typically focused on only one of these developmental disturbances at a time. A key problem with this approach is that it neglects the presence of widespread co-morbidities among learning disturbances (e.g., Landerl, Moll 2010) as well as with other developmental disturbances, such as oral language deficits, visuo-spatial disorders or ADHD (Pennington 2006).

Traditional cognitive research is not well suited to deal with co-morbidities since it adopted a narrow perspective focused on single deficits. A clear case at hand is the development of cognitive architectures in reading, such as the well-known dual route model, based on a separation between lexical and nonlexical routes (Coltheart et al. 2001), or the triangle model (Plaut et al. 1996; Seidenberg, McClelland 1989). Regardless of their different structures, none of these models can easily accommodate the presence of co-morbidities between reading and other developmental deficits because they focus on the specificity of the reading process; i.e., they try to make explicit the cognitive processes that are selectively active in order to account for different aspects of reading.

The distinction between proximal and distal causes is central to this type of theorizing (Coltheart 2015). Processes referring to proximal causes are described as the cognitive antecedents of reading (writing or maths): in this perspective, a model of reading is a complex architecture featuring the relationships between these proximal antecedents and reading. A wealth of more general cognitive processes (such as short and long memory, perception, attention and the like) are necessary to support the activity of the processes envisaged by the model but they are seen as distal processes to the extent in which no explicit relationship is put forward with the reading behaviour and with the proximal factors considered in the architecture of reading. In terms, their role on the target behaviour is expected to act indirectly to the extent in which they influence some of the proximal processes envisaged within the architecture.

Besides the narrower perspective focused on proximal processes, a long-lasting tradition of studies aimed to account for reading (but also writing and maths) deficits from a broader cognitive perspective, examined whether children with dyslexia have deficits in short-term memory (e.g., Swanson et al. 2009), executive processing (e.g., Helland, Asbjørnsen 2000), attention (e.g., Hari, Renvall 2001), rapid naming (e.g., Kirby et al. 2010), phonological awareness (e.g., Melby-Lervåg et al. 2012) and so on. These investigations can be broadly framed as studies examining the distal cognitive antecedents of specific learning disabilities. A strength of this approach is that it is not limited by the very specific constraints of cognitive architectures; a weakness is that broad categories, such as attention or memory, can interact in many different ways with complex behaviours, such as reading, writing or doing maths, and these relationships are left implicit within a distal perspective. As an effect of this, it is quite difficult to provide a theoretical synthesis of the studies examining the distal cognitive antecedents of specific learning disabilities.

\section{Proximal approach to study comorbidity}

Can the proximal approach be reformulated and extended to account for co-morbid disturbances? Notably, there are a few instances in which the question of how to account for a plurality of deficits has been examined in the cognitive literature. For example, in this vein is the controversy as to whether separate orthographic lexica have to be considered to account for reading and writing, or one can imagine 
that reading and writing both impinge on the same lexicon (Hillis, Rapp 2004). Thus, assuming the presence of a single lexicon for reading and writing might account at least in part for the presence of the (frequent) association between developmental reading and writing deficits.

At the same time, the presence of two partially different architectures provides the ground for also understanding the presence of dissociations between reading and writing deficits, as reported both in acquired and developmental cases. This example indicates that it is in principle possible to tackle developmental co-morbid deficits by cognitive architectures in a proximal perspective. Yet, it must also be noted that dyslexia and dysgraphia are very "close" (or homotypic) deficits and it is still to be proven that this approach can be extended to more "distant" (or heterotypic) comorbidities (such as reading and maths).

\section{Selecting the target behaviour: reading single word vs. functional reading}

An additional feature, which may dampen the possibility of cognitive models to account for co-morbid deficits (defined as associations among "complex behaviours"), is that they typically focus on a very simplified, abstract, nonecological condition of the target behaviour. For instance, models, such as the DRC model, aim to predict performance in single word reading aloud. However, fluent reading in a functional context, such as reading a text passage, requires more than efficient single word processing. Indeed, to read a text, the reader has to synchronize a number of ongoing processes (including programming saccades, acquiring information during fixations, maintaining the fixated word in short-term memory in order to pronounce it, etc.). Therefore, even in the absence of specific speed instructions, reading a text represents a task that inherently poses tight time constraints and requires synchronization of processing to the observers
Thus, the ability to process multiple targets is an important part of the reading process and may contribute to the dyslexic deficit over and above the deficit at the word level. One task that may capture such ability is the well-known Rapid Automatized Naming or RAN (Denckla, Rudel 1976). Here, the child has to quickly scan and name a large set of familiar targets (typically colours, objects, or numbers). A crucial finding in the literature on RAN is that the typical slowing of children with dyslexia with respect to typically developing readers is selective for multiple display conditions. If stimuli (colours, objects, or numbers) are singly presented, children with dyslexia are not (or minimally) impaired, and performance on discrete (single-item) RAN trials does not correlate with reading fluency (e.g., Georgiou et al. 2013).

Thus, we have proposed that RAN tasks mark the ability to integrate the subcomponents involved in reading from multiple displays, as typical of effective reading (Zoccolotti et al. 2014). One important feature of this proposal is that it interprets RAN in "proximal" terms, i.e., it makes it explicit the contribution of processes marked by RAN to reading, and reading from multiple word displays in particular, as typical of functional reading in everyday conditions. Evidence in support of a proximal interpretation of RAN comes from studies indicating that RAN makes an independent contribution to the prediction of reading fluency over and above measures of orthographic processing (Protopapas et al. 2013; Zoccolotti et al. 2014).

Overall, using reading a meaningful text as target behaviour appears a more ecological, less abstract condition with respect to single word reading. Furthermore, it should be kept in mind that co-morbidity is expected among "complex" behaviours (Pennington 2006) and an analysis based on highly selected measures (such as single word reading) may fail to capture this phenomenon. 
Associations and dissociations of reading and writing

Proposing that reading is a task with high time constrains provides a framework to interpret possible dissociations between reading and writing. Indeed, writing, which requires activation of orthographic and hand-motor processes, poses lesser time constraints and synchronization with respect to reading, and one does not expect that processes representing repetitive speeded processing, such as RAN, play a role in this case. On the converse, writing may also place particular constraints on the quality of the phonological representations to be converted into written output. This is true on both dictation and spontaneous writing conditions. Indeed, several authors posit that efficient writing requires fully specified phonological representations while reading may also take advantage from partial cue processing (Perfetti 1992; Tainturier, Rapp 2001).

This analysis poses the premises for an interpretation of reading and writing associations and dissociations as actually observed in clinical practice in terms of shared and independent processes. Thus, one working hypothesis could be that an efficient lexicon would be instrumental to both reading and writing, while performance on RAN should contribute to the prediction of reading but not writing. Some evidence goes in this direction (e.g., Moll, Landerl 2009). Conversely, efficient phonological processing may contribute predominantly (or only) to writing and less (or not) to reading.

\section{Comorbidity of reading and maths deficits}

A few studies considered comorbidity of reading and maths deficit; all these studies used a distal approach, which favours, as summarized above, the possibility of observing relationships between a factor and seemingly distant behaviours (Slot et al. 2016; Wilson et al. 2015; Cheng et al. 2018). A weakness of these studies is the feature characteristic of the distal approach, which generally fails to specify in explicit terms the relationship between a predictive factor and a behaviour (such as: why should verbal short-term memory predict literacy? Why should phonological processing predict maths?).

Overall, we thought important to envisage an analysis of developmental co-morbidities that, in a proximal perspective, would specify the processes exerting independent and shared influences on target behaviours. In our research on this matter, we started from a study on a group of typically developing children (Zoccolotti, De Luca, Marinelli, Spinelli, submitted).

As dependent variables, we measured performance in behaviours with a clear functional value in everyday life, such as reading a text, writing under dictation and doing mental and written computations. As predictors, we selected cognitive dimensions having an explicit relation with the target behaviour (called proximal predictors), and prepared various tests in order to select which task had the best predictive power on each behaviour. The aim was to develop a model of proximal predictors of reading (speed and accuracy), writing (accuracy) and maths (speed and accuracy) characterized by efficacy also in comparison to the prediction based on general cognitive factors and parsimony, pinpointing the role of both common and unique predictors as envisaged in the general perspective of co-morbidity.

\section{Experimental study}

An unselected sample of 129 (65 male, 64 female) Italian children (mean age $=$ 10.7 years; $\mathrm{SD}=0.3$; range $=10.1-11.3$ years) were examined. All children attended $5^{\text {th }}$ grade, had an adequate performance to the Raven CPM (Pruneti et al., 1996) and normal socioeducational conditions.

Tests. For reading, we used a text reading test (MT reading test; Cornoldi and Colpo, 1998) as dependent measure and as predictors different forms of RAN (De Luca et al., 2005) as well as three different tests of Orthographic decoding (requesting the Matching of Pseudowords in the Visual-visual, Visual-auditory, and in the Auditory-auditory modality). 
For Writing, we used a spelling-to-dictation test ("Nonna Concetta"; Marinelli et al., 2016). As predictors, we used the following tests: Single Pseudo-word Repetition and Phonemic Segmentation; Orthographic Decision (the child has to read silently regular and irregular words and immediately indicate whether or not they are correctly spelled), and a test of Repetition of Pseudo-word Series (Marinelli et al. 2018).

As for Numerical skills, two different dependent measures were used: Mental Calculation (from the AC-MT battery; Cornoldi et al. 2002) and Written Arithmetic Calculations (from AC-MT). As predictors, we used the following tests: Dictation of Numbers (from ACMT); Arabic Number Reading test (from the Developmental Dyscalculia Battery, DDB; Biancardi and Nicoletti 2004); Number Order test (from the AC-MT); Arithmetic Facts test (from DDB); Computation Strategies test (from ACMT); Computation Procedures (Tabulation and carry) and Backward Counting (from AC-MT battery).

Finally, a number of General cognitive predictors were considered as control tests: Symbol Search subtest (from the WISC-R; cognitive speed); Raven's Coloured Progressive Matrices (non-verbal intelligence); Forward and Backward Span of Numbers (from the BVN battery; Bisiacchi et al. 2005; verbal short-term memory) and Verbal Phonemic Fluency test (from the BVN Battery; verbal fluency).

\section{Results}

In order to detect the best model accounting for reading, writing and maths skills, we carried out a number of communality analyses. For all dependent measures it was possible to identify a proximal model explaining a sizeable amount of variance; this ranged from $27.5 \%$ in the case of calculation (accuracy) to $48.7 \%$ of reading (fluency). These data are presented in Table 1 (bold numbers) which also lists the specific predictors which entered in each of the models.
As a control we also tested models based on general cognitive abilities. Such models also accounted for some variance but this was appreciably less than that explained by models based on the hypothesized proximal predictors (Table 1, last column).

While models were generally effective in accounting for the different behaviours, results offered only limited support to a co-morbidity model, i.e. on accounting for the presence of comorbidities among different learning processes. We confirmed that the Orthographic Decision test entered in both reading and writing models (in keeping with the idea of a single lexicon for reading and writing). However, all other predictors were specific of single behaviours, i.e., different predictors were present for reading, writing and maths. Thus, from these analyses one could conclude that the models of reading, writing and calculation are "specific" to the extent in which a) they explain these behaviours with appreciably greater efficacy than general cognitive factors and b) they do so by using sets of predictors which mark different putative dimensions for different behaviours.

To submit these conclusions to an empirical test, we decided to further examine the specificity of the predictors by testing predictors over non-target behaviours. If the above conclusion were correct, using predictors in this cross-over manner should fail to effectively predict target behaviours. These hypotheses were tested by switching predictors over dependent measures; thus, we checked to what extent the predictors of reading accounted for writing and calculation and so on.

The outcome of these analyses is also summarized in Table 1 which presents the total variance accounted for by using the predictors in the models of reading, writing, and calculation when applied across all target behaviours. As one might expect, the specific predictors always yielded the highest estimate on the target behaviour. Thus, reading fluency was best accounted for by the predictors in the reading 
Table 1. Part A) Percentage of total variance explained by models based on different sets of predictors. Specific" predictions (i.e., reading dependent measure predicted by reading predictors etc.) are marked in bold. However, each specific set of predictors (for reading fluency, writing accuracy, calculation speed, and calculation accuracy) is also used to "cross"-predict the other target dependent measures

\begin{tabular}{|c|c|c|c|c|}
\hline \multirow{3}{*}{$\begin{array}{l}\text { Dependent } \\
\text { measures }\end{array}$} & \multicolumn{4}{|c|}{ Predictors } \\
\hline & $\begin{array}{l}\text { Reading } \\
\text { fluency }\end{array}$ & $\begin{array}{l}\text { Writing } \\
\text { accuracy }\end{array}$ & Calculation & $\begin{array}{l}\text { Cognitive } \\
\text { abilities }\end{array}$ \\
\hline & $\begin{array}{l}1 . \\
\text { Orthographic } \\
\text { decision } \\
\text { 2. RAN } \\
\text { 3. Visual- } \\
\text { auditory } \\
\text { pseudo-word } \\
\text { matching } \\
\end{array}$ & $\begin{array}{l}\text { 1. } \\
\text { Orthographic } \\
\text { decision } \\
\text { 2. Single } \\
\text { pseudo-word } \\
\text { repetition } \\
\text { 3. repetition of } \\
\text { pseudo-word } \\
\text { series }\end{array}$ & $\begin{array}{l}\text { 1. Number } \\
\text { order } \\
\text { 2. Arithmetic } \\
\text { facts } \\
3 \text {. } \\
\text { Computation } \\
\text { strategies }\end{array}$ & $\begin{array}{l}\text { 1. Raven } \\
\text { 2. Symbol } \\
\text { search } \\
\text { 3. Verbal } \\
\text { phonemic } \\
\text { fluency } \\
\text { 4. Backward } \\
\text { span }\end{array}$ \\
\hline Reading (fluency & 48.7 & 34.9 & 38.8 & 19.5 \\
\hline Writing (accuracy) & 21.1 & 29.2 & 18.6 & 6.5 \\
\hline Calculation (speed) & 31.9 & 18.1 & 37.9 & 12.8 \\
\hline $\begin{array}{l}\text { Calculation } \\
\text { (accuracy) }\end{array}$ & 19.4 & 20.2 & 27.5 & 12.8 \\
\hline
\end{tabular}

model and the same held for writing and calculation. However, inspection of the table also illustrates that putatively specific models predicted much more than one would expect (and much more than what accounted for by general cognitive predictors) of the "other" dependent measures. In fact, some of the values were surprisingly high. For example, predictors in the model of calculation accounted for $38.8 \%$ of the variance in reading fluency, a value only slightly inferior to the variance predicted by the model of reading itself (48.7\%).

We carried out further analyses (not presented here in detail) to understand which tests contributed most to this overlap in the predictions. Indeed, some predictors had a general influence across different behaviours; this was particularly the case of the Orthographic decision and Arithmetic facts tests. Both tests were "strong" predictors of the expected (related) behaviour but also of the other "unexpected" (unrelated) behaviours.

In spite of their surface characteristics, the Orthographic Decision and the Arithmetic Facts tests share the requirement of calling a specific trace from memory. In the case of maths, chil- dren first learn to make computations by applying an algorithm; then, by repetitive exposure to the solution of a given operation (such as "3 times 8"), they learn to directly access the solution of the operation (24) without application of the algorithm. In a similar vein, children first learn to apply grapheme-to-phoneme conversion rules to recognize words and through repetitive exposure to print, they slowly learn to directly access the target word (i.e., reading by "sight") without passing for the conversion of graphemes into phonemes.

Thus, both the Orthographic Decision and the Arithmetic Facts tests share the requirements to retrieve a trace in memory, which is a different process with respect to the application of a specific algorithm. A theory that formalizes the ability to retrieve easily and automatically a specific memory trace is the "Instance theory of automaticity" proposed by Logan (1992). According to this theory, automatization is acquired through repetitive presentation of a stimulus: in this way, the "instance representation" of an individual object or event is stored in memory ("obligatory encoding") and, the more repetitions, the more infor- 
mation becomes directly available ("obligatory retrieval"). By contrast, others tests predicted different behaviours but only for a specific parameter, such as speed but not accuracy (this was the case of RAN), and still others were specific for a single behaviour.

It appeared that these findings could not be easily fit into a framework considering a single level of explanation. Rather, we proposed that predictors acted at different levels of generality and such characteristic should be kept into account in trying to propose a comprehensive interpretation of co-morbidity. Thus, to interpret these results, we separately considered factors in terms of competence, performance and acquisition (automatization); this ap- proach seems suitable to account for comorbidity. In this view, reading, writing and calculation skills depend on the development of discrete and different abstract competences (accounting for partial dissociations among learning disorders). By contrast, overlap among behaviours (co-morbidity) would be accounted for by defective acquisition in automatized responses to individual "instances"; this latter skill would be item specific but domain general. Furthermore, performance factors may also contribute to co-morbidity among learning behaviours. It is proposed that this framework may represent a useful reference to guide research on the co-morbidity of learning disabilities.

\section{References}

Biancardi, A., Nicoletti, C. (2004) Batteria per la discalculia evolutiva (BDE): Omega. (In Italian)

Bisiacchi, P. S., Cendron, M., Gugliotta, M., Tressoldi, P. E., Vio, C. (2005) BVN 5-11: batteria di valutazione neuropsicologica per l'età evolutiva. Trento: Centro Studi Erickson. (In Italian)

Cheng, D., Xiao, Q., Chen, Q., Cui, J., Zhou, X. (2018) Dyslexia and dyscalculia are characterized by common visual perception deficits. Developmental neuropsychology, vol. 43 (6), pp. 497-507. (In English)

Coltheart, M. (2015) What kinds of things cause children's reading difficulties? Australian Journal of Learning Difficulties, vol. 20 (2), pp. 103-112. (In English)

Coltheart, M., Rastle, K., Perry, C., Langdon, R., Ziegler, J. C. (2001) DRC: A dual-route cascaded model of visual word recognition and reading aloud. Psychological Review, vol. 108 (1), pp. 204-256. (In English)

Cornoldi, C., Colpo, G. (1998) Prove di lettura M.T. per la scuola elementare - 2. Manuale. Firenze: Organizzazioni Speciali. (In Italian)

Cornoldi, C., Lucangeli, D., Bellina, M. (2002) AC-MT Test: Test per la valutazione delle difficoltà di calcolo. [The AC-MT arithmetic achievement test]. Trento, Italy: Erickson. (In Italian)

De Luca, M., Di Filippo, G., Judica, A., Spinelli, D., Zoccolotti, P. (2005). Test di denominazione rapida e ricerca visiva di colori, figure e numeri. [Online]. Available at: https://www.hsantalucia.it/sites/default/files/fsl_labdislessia_ran_ricerca_visiva_test.pdf (assessed 16.09.2019). (In Italian)

Denckla, M. B., Rudel, R. G. (1976) “Rapid automatized naming” (R.A.N.): dyslexia differentiated from other learning disabilities. Neuropsychologia, vol. 14 (4), pp. 471-479. (In English)

Georgiou, G. K., Parrila, R., Cui, Y., Papadopoulos, T. C. (2013) Why is rapid automatized naming related to reading? Journal of Experimental Child Psychology, vol. 115 (1), pp. 218-225. (In English)

Hari, R., Renvall, H. (2001) Impaired processing of rapid stimulus sequences in dyslexia. Trends in Cognitive Sciences, vol. 5(12), pp. 525-532. (In English) 
Helland, T., Asbjørnsen, A. (2000 Executive functions in dyslexia. Child Neuropsychology, vol. 6 (1), pp. 37-48. (In English)

Hillis, A. E., Rapp, B. C. (2004) Cognitive and neural substrates of written language: Comprehension and production. In: Gazzaniga, M. S. (ed.) The cognitive neurosciences II. Cambridge, MA: The MIT Press, pp. 775-787. (In English)

Kirby, J. R., Georgiou, G. K., Martinussen, R., Parrila, R. (2010) Naming speed and reading: From prediction to instruction. Reading Research Quarterly, vol. 45(3), pp. 341-362. (In English)

Landerl, K., Moll, K. (2010) Comorbidity of learning disorders: prevalence and familial transmission. Journal of Child Psychology and Psychiatry, vol. 51 (3), pp. 287-294. (In English)

Logan, G. D. (1992) Shapes of reaction-time distributions and shapes of learning curves: A test of the instance theory of automaticity. Journal of Experimental Psychology: Learning, Memory, and Cognition, vol. 18(5), pp. 883-914. (In English)

Marinelli, C. V., Judica, A., Cucciaioni, C., Verni, F., Deidda, C., Notarnicola et al. (2016) "Nonna Concetta": Una prova di dettato di brano per la valutazione delle abilità ortografiche nella scuola primaria. Psicologia Clinica dello Sviluppo, vol. 20 (3), pp. 425-449. (In Italian)

Marinelli, C.V., Putzolu, A., De Salvatore, M., Iaia, M., Angelelli, P. (2018) Developmental phonological dyslexia and dysgraphia in a regular orthography: a case study. JDREAM - Journal of interdisciplinary research applied to medicine, vol. 2, pp. 67-82. (In English)

Melby-Lervåg, M., Lyster, S. A. H., Hulme, C. (2012) Phonological skills and their role in learning to read: a meta-analytic review. Psychological Bulletin, vol. 138 (2), pp. 322-352. (In English)

Moll, K., Landerl, K. (2009) Double dissociation between reading and spelling deficits. Scientific Studies of Reading, vol. 13 (5), pp. 359-382. (In English)

Pennington, B. F. (2006) From single to multiple deficit models of developmental disorders. Cognition, vol. 101 (2), pp. 385-413. (In English)

Perfetti, C. A. (1992) The representation problem in reading acquisition. In: Gough, P. B., Ehri, L. C., Treiman R. (eds.) Reading acquisition. Hillsdale, NJ: Lawrence Erlbaum Associates, pp. 145-174. (In English)

Perry, C., Ziegler, J. C., Zorzi, M. (2007) Nested incremental modeling in the development of computational theories: the CDP+ model of reading aloud. Psychological Review, vol. 114 (2), pp. 273-315. (In English)

Plaut, D. C., McClelland, J. L., Seidenberg, M. S., Patterson, K. (1996) Understanding normal and impaired word reading: Computational principles in quasi- regular domains. Psychological Review, vol. 103 (1), pp. 56-115. (In English)

Protopapas, A., Altani, A., Georgiou, G. K. (2013) Development of serial processing in reading and rapid naming. Journal of Experimental Child Psychology, vol. 116 (4), pp. 914-929. (In English)

Pruneti C., Fenu A., Freschi G., Rota S., Cocci D., Marchionni M. et al. (1996) Aggiornamento della standardizzazione italiana del test delle Matrici Progressive Colorate di Raven (CPM). Bollettino di Psicologia Applicata, vol. 217, pp. 51-57. (In Italian)

Seidenberg, M. S., McClelland, J. L. (1989) A distributed, developmental model of word recognition and naming. Psychological Review, vol. 96 (4), pp. 523-568. (In English)

Slot, E. M., van Viersen, S., de Bree, E. H., Kroesbergen, E. H. (2016). Shared and unique risk factors underlying mathematical disability and reading and spelling disability. Frontiers in Psychology, vol. 7, p. 803. (In English)

Swanson, H. L., Zheng, X., Jerman, O. (2009). Working memory, short-term memory, and reading disabilities: A selective meta-analysis of the literature. Journal of Learning Disabilities, vol. 42 (3), pp. 260-287. (In English) 
Tainturier, M. J., \& Rapp, B. (2001). Spelling words. In: Rapp, B. (Ed.) What deficits reveal about the human mind/brain: A handbook of cognitive neuropsychology. Philadelphia, PA: Psychology Press. pp. 263-289. (In English)

Wilson, A. J., Andrewes, S. G., Struthers, H., Rowe, V. M., Bogdanovic, R., Waldie, K. E. (2015). Dyscalculia and dyslexia in adults: cognitive bases of comorbidity. Learning and Individual Differences, vol. 37, pp. 118-132. (In English)

Zoccolotti, P., De Luca, M., Marinelli, C. V., \& Spinelli, D. (2014). Modeling individual differences in text reading fluency: data from proficient and dyslexic readers. Frontiers in Psychology, vol. 5, p. 1374. (In English)

Zoccolotti, P., De Luca, M., Di Filippo, G., Marinelli, C. V., Spinelli, D. (submitted). Toward a proximal cognitive model of co-morbidity: Predicting individual differences in reading, writing and maths. (In English) 